\title{
Interação Teleatendente-Teleusuário e Custo Humano do Trabalho em Central de Teleatendimento
}

\section{Interaction Call Center Workers-Call Center Users and the Human Cost of Work in a Call Center Unit} Universidade de Brasilia-UnB,
Instituto de Psicologia, Laboratório de
Ergonomia

\begin{abstract}
O texto aborda uma pesquisa realizada em uma central de teleatendimento do setor público. A análise ergonômica orienta-se para a interação teleatendente-teleusuário, buscando mostrar as características da organização do trabalho que constrangem as estratégias de mediação dos operadores e potencializam a ocorrência de vivências de mal-estar no trabalho. $O$ referencial teórico-metodológico articula os conceitos de custo humano do trabalho, vivências de bem-estar e mal-estar e a Análise Ergonômica do Trabalho - AET. Os resultados mostram as características da Central e principais indicadores críticos, revelando um nexo entre custo humano do atividade e indícios de vivências de mal-estar dos operadores.
\end{abstract}

Palavras-chave: central de teleatendimento, custo humano do trabalho, interação, teleatendente, teleusuário, ergonomia da atividade.

The text shows a research done in a public call center unit. The ergonomic analysis is oriented toward the interaction call center worker-call center user, aiming to present the characteristics of the work organization that constraint the strategies of mediation of the call center workers and that may result in discomfort of well-being at work. The theoretical and methodological approach deals with the concepts of human cost of work, well-being and discomfort of well-being, and the Ergonomics Analysis of Work -EAW. The results show the characteristics of the call center unit and its main critical indicators, revealing a connection between the human cost of the activity and signals of discomfort of well-being among the call center workers.

Keywords: call center unit, human cost of life, interaction, call center worker, call center user, ergonomic of activity. 


\section{Introduc̣ão}

O objetivo do artigo é mostrar, com base em pesquisa em Ergonomia da Atividade, 0 surgimento de indícios de vivências de malestar em teleatendentes que trabalham em centrais de teleatendimento como uma resultante da inter-relação modelo de gestão e custo humano do trabalho.

Nessa perspectiva, o foco da análise ergonômica está centrado na interação teleatendente-teleusuário, buscando evidenciar as características da organização do trabalho que reduzem as estratégias de mediação no trabalho e potencializam a ocorrência de vivências de mal-estar no trabalho. A importância da temática articula aspectos distintos.

Do ponto de vista mais geral, os serviços de teleatendimento têm crescido no mundo todo. No Brasil, alguns indicadores relativos a 2002 são eloqüentes: há cerca de 180 mil postos de teleatendimento; o setor gera aproximadamente 450 mil empregos e movimenta anualmente por volta de US $\$ 1,2$ bilhão. O "cardápio" de serviços é variado: pesquisa; televendas; cobranças; promoções; construção de bancos de dados; fidelização de clientes etc. Do ponto de vista institucional, em particular para as organizações públicas e privadas, a avaliação científica de contextos de teleatendimento pode contribuir para aprimorar os modelos de gestão do trabaIho, agregando qualidade final aos serviços prestados e, em conseqüência, impactando na satisfação de usuários e clientes, tendo como pressuposto o bem-estar das pessoas que trabalham no setor. Finalmente, do ponto de vista científico, embora a "neurose das telefonistas" (Le Guillant et al., 1956) seja largamente conhecida há mais de meio século, os serviços de teleatendimento e suas implicações humanas no campo da inter-relação trabalho-saúde permanecem pouco investigados, sobretudo após a avalanche de inovações tecnológicas que assolam o mundo do trabalho. Deste modo, a produção de estudos e pesquisas em Ergonomia da Atividade podem contribuir para a produção de novos conhecimentos teórico-metodológicos e práticos nesta área.

\section{Quadro teórico de referência}

Globalmente, constata-se que os estudos internacionais têm focado mais as variáveis relacionadas à lógica de funcionamento das centrais, aos indicadores diversos de produtividade, à gestão rigorosa de desempenho dos teleatendentes, à satisfação e à fidelização dos usuários (Chang \& Huang, 2000; Gilmore \& Moreland, 2000).

Nesse sentido, os aspectos relacionados às condições de trabalho (no sentido amplo, transcendendo os componentes da plataforma de trabalho), as exigências das tarefas em termos de dispêndios dos trabalhadores e, ainda, as conseqüências sobre o bem-estar de teleatendentes permanecem assuntos marginais na literatura.

Os poucos estudos realizados no Brasil têm evidenciado um cenário mais rico referente às características das centrais, com ênfase nos fatores relacionados às situações de trabalho e suas conseqüências sobre os operadores. A incidência de Lesões por Esforços Repetitivos - LER - entre trabalhadores de centrais de teleatendimento é examinada na literatura (Marx, 2000; Lima, 2000). O caráter complexo das atividades de teleatendimento é argumentado por MASCIA E SZNELWAR (2000). O ambiente físico, sobretudo a falta de tratamento acústico, a iluminação deficiente, a existência de poeira, a falta de limpeza, as interfaces computacionais pouco amigáveis e o mobiliário inadequado constituem ingredientes das condições de trabalho que repercutem na carga de trabalho, conforme estudo de avaliação ergonômica em nove centrais de atendimento realizado por Santos et al. (2000). Perdas auditivas induzidas por ruído, más condições de conservação dos equipamentos e mobiliário inadequado foram constatados também por Bernadi et al. (2000).

Os principais fatores de estresse, configurando uma sobrecarga emocional, cognitiva e física entre operadores de telemarketing são caracterizados por Glina \& Rocha (2003). Tais resultados parecem confirmar que a utopia flexível, propalada pelos novos modelos de gestão, ainda é uma realidade distante no 
contexto de call center (Azevedo \& Caldas, 2002).

O referencial teórico da pesquisa articula os conceitos de custo humano do trabalho e vivências de bem-estar e mal-estar (Ferreira \& Mendes, 2003).

As condições, a organização e as relações sociais de trabalho são fios que tecem o conceito de contexto de produção de bens e prestação de serviços. Eles expressam os parâmetros básicos que são configuradores das fontes do "Custo Humano do Trabalho $\mathrm{CHT}^{\prime}$. As estratégias de mediação individuais e coletivas dos trabalhadores assumem contornos mais definidos e finalístico com base nesses parâmetros.

O conceito de $\mathrm{CHT}$ expressa o que deve ser despendido pelos trabalhadores (individual e coletivamente) nas esferas física, cognitiva e afetiva vis-à-vis às contradições existentes nas organizações que obstaculizam (pólo negativo do custo) e desafiam (pólo positivo do custo) a inteligência dos trabalhadores (Ferreira \& Mendes, 2003). Nessa perspectiva teórica, o CHT se caracteriza por três propriedades principais:

é imposto externamente aos trabalhadores sob a forma de constrangimentos (contraintes) para suas atividades;

- é gerido por meio das estratégias de mediação individuais e coletivas, podendo assumir as formas de confrontações positivas ou negativas que, por sua vez, impactam na dinâmica das vivências de bem-estar e mal-estar no trabalho; e

- integra três modalidades interdependentes de exigências: física, cognitiva e afetiva.

As exigências que constituem a noção de $\mathrm{CHT}$ estão assim definidas (Ferreira \& Mendes, 2003):

(a) exigências físicas expressam o custo corporal que é imposto aos trabalhadores pelas características do ambiente de trabalho em termos de dispêndios fisiológico e biomecânico, principalmente sob a forma de posturas, gestos, deslocamentos e emprego de força física;

(b) exigências cognitivas expressam o custo cognitivo que é imposto aos trabalhadores pelas características do ambiente de trabalho em termos de dispêndio mental sob a forma de aprendizagem necessária, resolução de problemas e tomada de decisão; e

(c) exigências afetivas expressam o custo afetivo que é imposto aos trabalhadores pelas características do ambiente de trabalho em termos de dispêndio emocional sob a forma de reações afetivas, sentimentos e estados de humor.

Evidentemente que o $\mathrm{CHT}$ mantém estreita relação com a atividade dos trabalhadores, orientando o desenvolvimento das estratégias de mediação individuais e coletivas, abrangendo as propriedades humanas do pensar, do agir e do sentir que, por sua vez, caracterizam e traçam os perfis dos modos de ser e viver dos trabalhadores nos contextos de produção de bens e prestação de serviços.

A perspectiva da pesquisa não foi propriamente mensurar o custo humano do trabatho das teleatendentes e seus indicadores, mas mapear de forma exploratória as exigências presentes no serviço de teleatendimento que caracterizam o dispêndio do grupo analisado.

Por último, cabe explicitar o entendimento conceitual adotado para a dimensão "vivências de mal-estar no trabalho". Trata-se de uma noção que é parte integrante do enfoque de "vivências de bem-estar e mal-estar" em Ergonomia da Atividade (Ferreira \& Mendes, 2003).

Nessa perspectiva conceitual, essas vivências se expressam por meio das representações mentais que os trabalhadores têm do próprio estado geral (físico, psicológico e social) em que se encontram em determinados momentos e contextos. Assim, as representações de bem-estar consistem em avaliações positivas e as representações de malestar, por sua vez, consistem em avaliações negativas que os trabalhadores expressam sobre suas condições física, psicológica e 
social relativas ao contexto de produção no qual estão inseridos.

As características principais das vivências de bem-estar e mal-estar são:

(a) o conteúdo das representações se refere às conseqüências individuais e coletivas do $\mathrm{CHT}$;

(b) elas têm um caráter dinâmico que resulta do confronto entre as exigências físico-cognitivo-afetivas inerentes ao ambiente de trabalho e as estratégias de mediação individuais e coletivas dos trabalhadores;

(c) as representações de bem-estar e malestar se caracterizam por uma dinâmi$\mathrm{ca}$, metaforicamente, à maneira de um pêndulo que tende a oscilar no eixo do processo saúde-doença. O movimento pendular depende da eficiência e da eficácia das estratégias de mediação.

O "efeito pêndulo" mantém, portanto, estreita relação com as atividades dos trabaIhadores nos sentidos de:

quanto mais eficientes e eficazes forem as estratégias de mediação individuais e coletivas dos trabalhadores, menor será - CHT, o que cria as condições para o predomínio de vivências de bem-estar individual e coletivo;

- quanto menos eficientes e eficazes forem as estratégias de mediação individuais e coletivas dos trabalhadores, maior será - CHT, o que cria as condições para o predomínio de vivências de mal-estar individual e coletivo.

No caso desta pesquisa, o uso dessa conceituação se orienta para a identificação e a caracterização das representações mentais que os teleatendentes têm do próprio estado geral (físico, psicológico e social) em que se encontram como decorrência do contexto de produção de serviços no qual eles estão "imersos". O acesso a essas representações se dará por meio da análise das verbalizações das teleatendentes acerca do próprio trabalho (Lacoste, 1995) e, em par- ticular, dos efeitos que este parece produzir nestes trabalhadores.

\section{Abordagem metodológica}

O enfoque metodológico foi a Análise Ergonômica do Trabalho - AET (Guérin et al., 2001). Os traços característicos do enfoque sustentam-se no paradigma de que a natureza do objeto de investigação (interrelação indivíduo-trabalho) subordina o método, seu instrumental e seus procedimentos.

O uso desse enfoque é orientado por cinco pressupostos:

- tem como ponto de partida a análise de uma situação-problema;

- apóia-se na participação efetiva dos envolvidos direta ou indiretamente com a pesquisa;

- livre acesso a todas informações atinentes à situação-problema;

- valoriza a variabilidade intra e interindividual do sujeitos, bem como do contexto sociotécnico; e

análise da atividade dos trabalhadores em situações reais de trabalho.

A AET não se coloca, portanto, como um "receituário" predefinido, uma vez que cada contexto de trabalho é singular e a complexidade das situações transforma o diagnóstico científico em um verdadeiro quebra-cabeça, conforme metáfora apresentada na figura 1 (Ferreira, 2003).

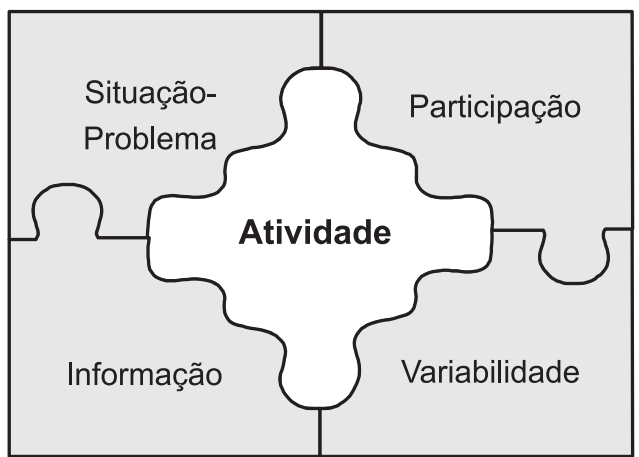

Figura 1 Metáfora do quebra-cabeça caracterizando os pressupostos da análise ergonômica do trabalho. 
Todos os participantes da pesquisa $(\mathrm{N}=40)$ são do gênero feminino e trabalham em dois turnos, das $8 \mathrm{~h}$ às $13 \mathrm{~h} 30 \mathrm{~m}$ e das $13 \mathrm{~h} 30 \mathrm{~m}$ às 19h. Trata-se de uma população de mulheres trabalhadoras jovens, com idade variando de 20 a 30 anos, havendo predomínio de solteiras, com escolaridade distribuída, principalmente entre o Ensino Médio (antigo $2^{\circ}$ grau completo) e curso superior incompleto. A maioria possui mais de quatro anos de experiência de trabalho em teleatendimento $e$ há um predomínio das que possuem de um a dois anos de trabalho na central onde se realizou a pesquisa. O grupo é portador de um tempo de vivência no trabalho em teleatendimento que serve de base para a análise da temática da pesquisa.

Os instrumentos e os procedimentos foram os habituais na démarche metodológica em Ergonomia da Atividade: análise documental, entrevista semi-estruturada, observações livres e sistemáticas das situações e atividades de trabalho.

\section{Principais resultados e discussão}

Pode-se depreender que a central foi concebida como sendo um canal de ligação direta entre os cidadãos e o órgão público. Os idealizadores a projetaram como um instrumento de comunicação social por meio do qual os cidadãos-usuários pudessem entrar em contato verbal com o órgão, sem ônus financeiro suplementar, para:

- efetuar consultas sobre questões diversas;

- solicitar materiais e informações;

- fazer denúncias;

- fazer reclamações; e

- dar sugestões.

A análise documental possibilitou situar a importância da central como ferramenta estratégica de atendimento ao público do órgão, exercendo um importante papel de comunicação social com a comunidade de usuários.

A evolução crescente das ligações se deve, sobretudo, aos seguintes aspectos: (a) a central atende cerca de 20 mil ligações diaria- mente. Destas, cerca de $20 \%$ são atendidas diretamente pelas teleatendentes e o restante, automaticamente pela Unidade de Resposta Audivel - URA; (b) cerca de 99\% das chamadas são respondidas em tempo real; (c) as consultas que requerem pesquisa são respondidas por cartas, enviadas aos teleusuários; (d) o tempo médio de duração das chamadas é de três minutos; (e) cerca de quinze teleusuários esperam pelo atendimento ouvindo propaganda institucional (jingles) dos programas do órgão público; (f) o tempo de espera na telefila é estimado em cinco minutos; e (g) todas as ligações são registradas via digitação. As chamadas feitas de celulares são bloqueadas. Isso reduziv em cerca de $30 \%$ o custo financeiro da central, mas também restringiu na mesma proporção uma opção de acesso aos serviços pelos usuários.

A gestão dos serviços da central se depara também com um problema já conhecido no contexto de teleatendimento com as características desta central (exemplo: informações com certo grau de complexidade de conteúdo, diversidade socioeconômica de usuários): a contradição entre quantidade de chamadas versus qualidade do teleatendimento. Nesse sentido, o tempo de duração do teleatendimento não é um parâmetro de qualidade absolutamente confiável na avaliação dos serviços.

A análise documental do "Manual de Teleatendimento" evidenciou o perfil esperado do desempenho da teleatendente: saber escutar, demonstrar segurança na resposta, evitar certos termos e expressões, argumentar com clareza, não conversar com os colegas, não se alimentar no posto de trabalho, mantê-lo organizado e não se ausentar do mesmo. Tais aspectos dão visibilidade aos parâmetros que orientam a conduta das teleatendentes nas situações de atendimento sob a ótica dos gestores do trabalho.

No que tange às condições de trabalho, identificou-se diversos indicadores críticos relativos a:

equipamentos arquitetônicos deteriorados;

níveis inadequados de ruído e iluminação; e

mobiliário deficiente dos postos de trabalho. 
No conjunto, tais fatores se afastam daquilo que estabelece a legislação vigente, bem como o que recomenda os manuais de Ergonomia (lida, 1990; Grandjean, 1998). Trata-se de aspectos que deterioram a qualidade do ambiente de trabalho e colocam em risco o bem-estar dos trabalhadores.

Um período de observação livre (1h) possibilitou a realização de um primeiro reconhecimento das situações reais de teleatendimento, por meio da escuta autorizada de ligações, sobretudo dos aspectos de interação teleatendentes-teleusuários. Nessa ocasião, realizou-se a adaptação de uma planilha de observação sistemática construída e validada em outro estudo semelhante (Freire, 2002) e revalidada pelos teleatendentes que participaram desta pesquisa.

Além de levantar os dados relativos às condutas verbais dos teleusuários, buscou-se também quantificar outras informações complementares que pudessem fornecer pistas sobre o custo humano do trabalho em teleatendimento. Assim, foram coletados dados concernentes: (a) aos tipos de ligações (exemplos: denúncias, trotes, reclamações); e (b) à ocorrência de eventos críticos (exemplos: queda de ligação, abandono, site fora do ar).

Planejou-se a observação sistemática com base nos seguintes critérios: (a) dois turnos da jornada de trabalho; (b) três dias intercalados de uma mesma semana (segunda, quarta e sexta-feira); (c) duração de uma hora, nos períodos das $10 \mathrm{~h}$ às $11 \mathrm{~h}$ e das $15 \mathrm{~h}$ às 16h, para cobrir os dois turnos; (d) escuta aleatória dos postos de trabalhos, programada automaticamente pelo Distribuidor Automático de Chamadas (DAC). A definição de tais critérios buscou contemplar elementos básicos de variabilidade (exemplo: turnos) para aumentar o grau de confiabilidade dos dados coletados.

Os resultados relativos aos tipos de ligação e aos assuntos mais solicitados pelos teleusuários mostram:

- quanto ao tipo de ligação, se se sobressem "pedidos de informação (sem script)", ou sseja, se a maioria absoluta dos teleusuários solicitou informações que permitiram às teleatendentes responderem sem ajuda de script (textos preparados para respostas padronizadas). Se por um lado esse resultado parece reduzir o custo cognitivo do trabalho (redução do tratamento de informações, por exemplo), por outro ele fornece indícios sobre a repetitividade do trabatho e, em conseqüência, o aumento do custo afetivo em função do sentimento negativo de monotonia (Grandjean, 1998).

- que, embora numericamente pouco significativo, observa-se a ocorrência de ligações do tipo trote, denúncia e reclamação que exigem das teleatendentes estratégias singulares de mediação, cujo fracasso pode impactar negativamente no custo humano do trabalho, sobretudo na esfera afetiva (por exemplo, a conduta pouco cortês de um reclamante);

- quanto ao tipos de assuntos mais solicitados, os resultados mostram a diversidade de demanda dos teleusuários, permitindo-se supor que tal diversidade de informações requer o desenvolvimento de competências específicas no campo do diagnóstico, do tratamento e da tomada de decisão para responder eficientemente às demandas dos teleusuários em contexto de forte pressão temporal e de desempenho vigiado;

os eventos críticos ocorridos durante o período de observação nas situações de teleatendimento, embora quantitativamente pouco expressivo, evidenciam alguns elementos da complexidade do trabalho que impõe a construção de estratégias de mediação específicas para reduzir as conseqüências negativas nas dimensões afetiva e cognitiva do custo humano do trabalho. Por exemplo, explicar para um teleusuário com baixa escolaridade (ansioso por uma resposta) que o site (fonte da informação) está fora do ar requer um savoir-faire eficaz. Este resultado encontra eco na literatura, pois, em inúmeras situações em que os teleatendentes não dispõem de informações (totais ou parciais), o risco de que elas resultem em erros aumenta e, em conseqüência, há perda de qualidade dos serviços (Mascia \& Sznelwar, 2000).

Em relação às condutas verbais dos teleusuários nas situações de teleatendimento, 
alguns aspectos merecem ser assinalados:

- observou-se um nítido predomínio de teleusuários cuja conduta se caracteriza por ser cortês (agradece no final da ligação, utiliza "por favor", diz obrigado ao final da ligação e trata o teleatendente com respeito), ou seja, do ponto de vista quantitativo, parecem indicar pouco esforço operatório para cumprir as tarefas. Todavia, o caráter repetitivo, já assinalado, parece inexorável;

- os resultados mostram aspectos que podem estar na origem de indícios de mal-estar que resultam das exigências (cognitivas e afetivas) em lidar com teleusuários cuja conduta verbal se caracteriza por ser "desconhecedor do serviço", "não saber o que quer" (apresenta discurso desordenado, não se lembra das informações, não sabe o nome das coisas, não encontra palavras) e ser "prolixo" (prolonga a conversa, não é objetivo e fornece informações irrelevantes).

Em síntese, os resultados obtidos possibilitaram um aprofundamento maior na realidade do serviço de teleatendimento na central com base em dados característicos das situações que podem funcionar, principalmente, como constrangedores das atividades das teleatendentes. A natureza do trabalho de teleatendimento pôde ser melhor visualizada evidenciando fortes exigências cognitivas e afetivas para executar satisfatoriamente a prescrição do trabalho.

Os dados das entrevistas com teleatendentes $(\mathrm{N}=40)$ foram submetidos ao tratamento do aplicativo Alceste (Reinert, 1990). O tratamento do corpus identificou quatro classes temáticas estruturadoras das verbalizações das teleatendentes (Figura 2). Tais verbalizações expressam as representações operativas (Weill-Fassina et al., 1993; Teiger, 1993) que fazem parte do contexto de produção da central de teleatendimento em termos de linguagem sobre o trabalho e suas conseqüências (Lacoste, 1995). Trata-se de uma espécie de vision du monde no sentido atribuído por Max Reinert. Neste caso, uma visão do mundo do trabalho e de seus efeitos sobre as próprias teleatendentes.

A sensação de fadiga, esgotamento ou, como afirmam as atendentes, de estresse parece predominar nas representações que elas explicitam em relação ao estado geral em função de contextos de trabalho que vivenciam.

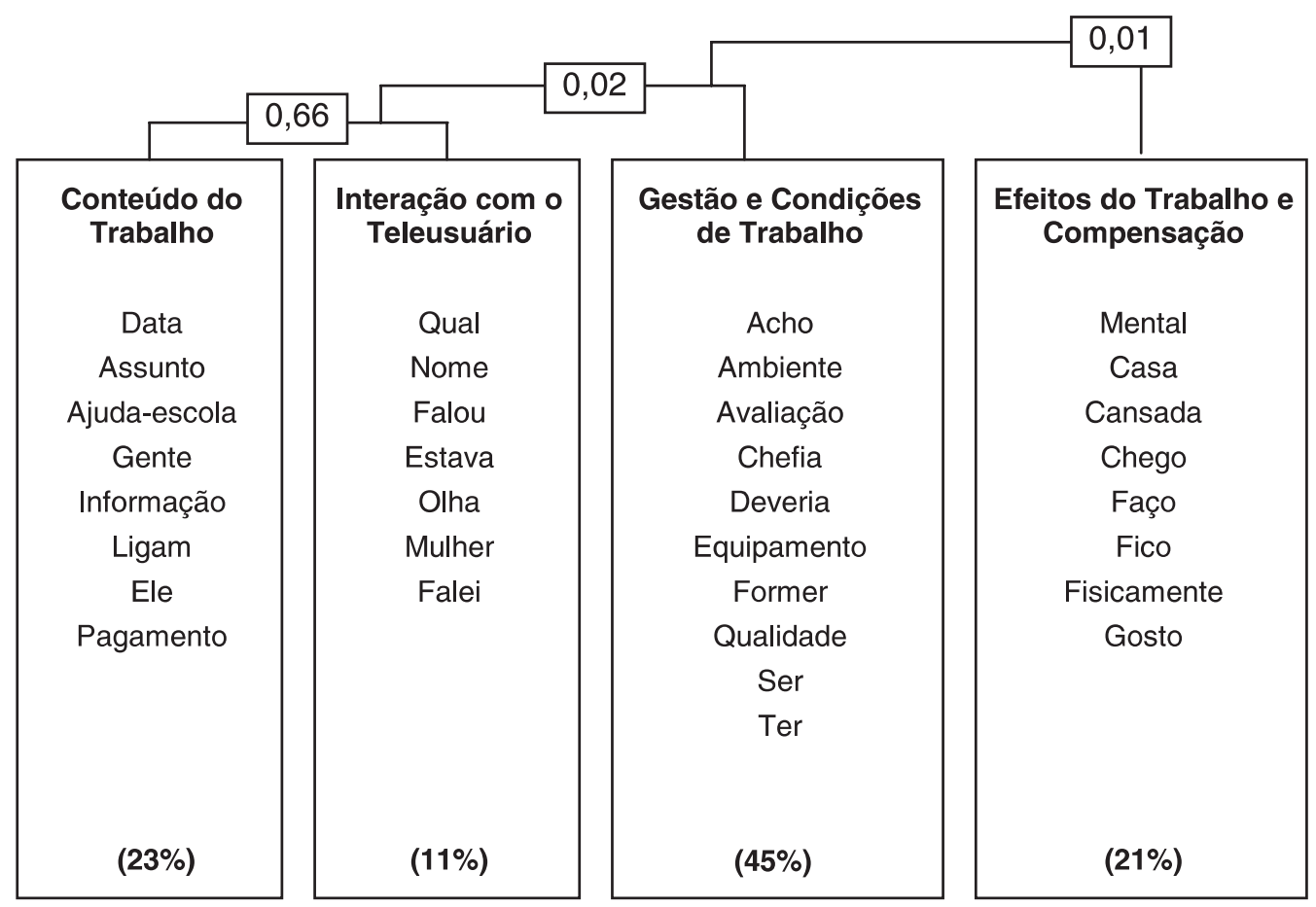

Figura 2 Classes Temáticas e Vocabulário Estruturador das Verbalizações das Teleatendentes. 
Nesse sentido, o traço negativo que caracteriza as avaliações que as teleatendentes fazem sobre seus estados físico, psicológico e social relativos ao contexto de serviço de teleatendimento no qual estão inseridas é revelador de vivências de mal-estar.

Todavia, esses indícios de vivências de malestar das teleatendentes parecem manter claras as relações com os resultados obtidos ao longo da pesquisa. Desse modo, os dados do perfil da central apontaram elementos de crescimento dos serviços sem a necessária correspondência em termos de suporte organizacional.

Diversos indicadores críticos foram evidenciados pela vistoria ergonômica, desenhando um cenário nada favorável ao predomínio de vivências de bem-estar no trabalho. Por fim, ao falarem do próprio trabalho, as teleatendentes agregaram um elenco de informações que configurou as principais fontes do pólo negativo do custo humano do trabalho, em particular a estreita relação entre o conteúdo do trabalho (significativa exigência cognitiva) e a conduta verbal dos teleusuários (significativa exigência afetiva), bem como o estilo de gestão e as condições de trabalho, combinando uma "mistura explosiva".

\section{Conclusão}

Os resultados mostram que a combinação de dimensões, condições, organização e rela- ções sociais de trabalho configura um cenário explicativo dos limites impostos às teleatendentes para mediar eficientemente a complexidade que marca a interação com os teleusuários e, ao mesmo tempo, a garantia dos objetivos prescritos e a preservação da saúde. É nesse cenário em que as vivências de mal-estar das teleatendentes assumem inteligibilidade, situação em que o trabalho se afasta de seu caráter ontológico de construção da identidade e de fonte de prazer. A análise dos resultados lança luz para se compreender os altos índices de rotatividade neste setor, cuja abordagem de gestão tem nos trabalhadores a variável de ajuste.

A discussão dos resultados possibilita identificar que a tensão entre o "velho" e o "novo" é um dos traços mais marcantes nos contextos de trabalho das centrais de teleatendimento. Ao mesmo tempo em que o teleatendimento é um setor que envolve a mais avançada tecnologia da informação e das telecomunicações, é também um dos ambientes onde o estilo de gestão do trabalho pode se dar da maneira mais arcaica e burocráti$\mathrm{ca}$, remetendo aos modelos industriais e tayloristas de administração do século passado. Nesse sentido, o texto "A neurose das telefonistas", que nasceu dos estudos de Le Guillant et al. (1956), permanece, sob o ângulo da organização do trabalho, bastante atual.

\section{Referências Bibliográficas}

AZEVEDO, M. C. \& CALDAS, M. P. Seriam os Call Centers os Sweatshops do Século XXI? In: Anais Realidade Organizacional. PROPAD/UFPE. ANPAD, 1 CD, 2002.

BERNADI, A. P., et al. Trabalho por Telefone Associado ao Uso de Computador (Telework): Estudo de Caso. In: L. I. Sznelwar \& L. N. Zidan (orgs.). O Trabalho Humano com Sistemas Informatizados no Setor de Serviços. São Paulo: Plêiade, 2000, pp. 209-221.

CHANG, Z. Y. \& HUANG, L. H. Quality deployment for the management of customer calls. Managing Service Quality, Bedford, v. 10, n. 2, pp. 98102, 2000.

FERREIRA, M. C. \& MENDES A. M. Trabatho e riscos de adoecimento: $O$ caso dos auditores-fiscais da Previdência Social brasileira. Brasília: Edições Ler, Pensar, Agir (LPA), 2003.

FERREIRA, M. C. O Sujeito Forja o Ambiente, o Ambiente "Forja" o Sujeito: Inter-Relação Indivíduo-Ambiente em Ergonomia da Atividade. In: M. C. Ferreira \& S. Dal Rosso (orgs.), A Regulação Social do Trabalho. Brasília, UnB: Editora Paralelo 15, 2003, pp. 21-45. 
FREIRE, O. N. "Ser Atendente a Vida Toda é Humanamente Impossível": Serviço de Teleatendimento e Custo Humano do Trabalho. 2002. Dissertação de Mestrado em Psicologia, Brasília - DF: Universidade de Psicologia.

FRIGERI F. Estudo dos Distúrbios MúsculoEsqueléticos Relacionados ao Trabalho em um Call Center. 2000. Dissertação de Mestrado em Engenharia de Produção. Rio de Janeiro: Universidade Federal do Rio de Janeiro.

GILMORE, A. \& MORELAND, L. How Can Service Quality be Managed? Irish Marketing Review, Dublin, v. 13, n. 1, 2000, pp. 3-11.

GLINA, D. M. R. \& ROCHA, L. E. Fatores de Estresse no Trabalho de Operadores de Centrais de Atendimento Telefônico de um Banco em São Paulo. Revista Brasileira de Medicina e Trabalho, Belo Horizonte, v. 1, n. 1, pp. 31-39, jul-set.,2003.

GRANDJEAN, E. Manual de Ergonomia. Adaptando o Trabalho ao Homem. 4 ed. Porto Alegre: Artes Médicas, 1998.

GUÉRIN, F., et al. Compreender o TrabaIho para Transformá-lo. A Prática da Ergonomia. São Paulo: Edgard Blücher, 2001

IIDA, I. Ergonomia. Projeto e Produção. São Paulo: Edgard Blücher, 1990.

LACOSTE, M. Parole, Action, Situação. In: Josiane Boutet (org.), Paroles au travail. Paris: L'Harmattan, 1995.

LE GUILLANT, et al. La Névrose des Téléphonistes. In: (org.) Quelle psyquiatrie pour notre temps? Travaux et écrits. Toulouse: Éditions Érès, 1956, pp. 379-391.

LIMA, M. E. A. Informatização e Saúde no Setor de Telecomunicações. O Problema das Lesõs por Esforços Repetitivos. In: L. I. Sznelwar \& L. N. Zidan (orgs.). O
Trabalho Humano com Sistemas Informatizados no Setor de Serviços. São Paulo: Plêiade, 2000, pp. 159-168.

MARX, R. (LER e Organização do Trabalho no Setor de Serviços: O Caso de Call Centers em Atendimento de Serviços Financeiros. In: L. I. Sznelwar \& L. N. Zidan (orgs.). O Trabalho Humano com Sistemas Informatizados no Setor de Serviços. São Paulo: Plêiade, 2000, pp. 8186.

MASCIA, F. L. e SZNELWAR, L. I. (2000). Diálogo e Constrangimentos do Scriptna Atividade de Atendimento a Clientes. In: L. I. Sznelwar \& L. N. Zidan (orgs.). O Trabalho Humano com Sistemas Informatizados no Setor de Serviços. São Paulo: Plêiade, 2000, pp. 97-104.

REINERT, M. (1990). Alceste, une méthodologie d'analyse des données textuelles et une application: Aurélia de Gérard de Nerval. Bulletin de méthodologie sociologique, n. 26 , pp. 24-54.

SANTOS, V. et al. Projeto Ergonômico de Centrais de Teleatendimento. In: L. I. Sznelwar \& L.N. Zidan (orgs.). O Trabalho Humano com Sistemas Informatizados no Setor de Serviços. São Paulo: Plêiade, 2000, pp. 235-246.

TEIGER, C. Représentation du travail. Travail de la représentation. In: A. Weiil-Fassina; P. Rabardel \& D. Dubois (orgs.). Représentations pour l'action, Toulouse, France: Ocatarès Editions, 1993, pp. 311-344.

TESSLER, J. S. Macroergonomia em Call Center de Ambiente Universitário. 2002. Dissertação de Mestrado profissionalizante em Engenharia. Universidade Federal do Rio Grande do Sul, Porto Alegre.

WEILL-FASINA, A., RABARDEL, P. \& DUBOIS, D. (orgs.). Représentations pour l'action, Toulouse, France: Octarès Editions, 1993. 